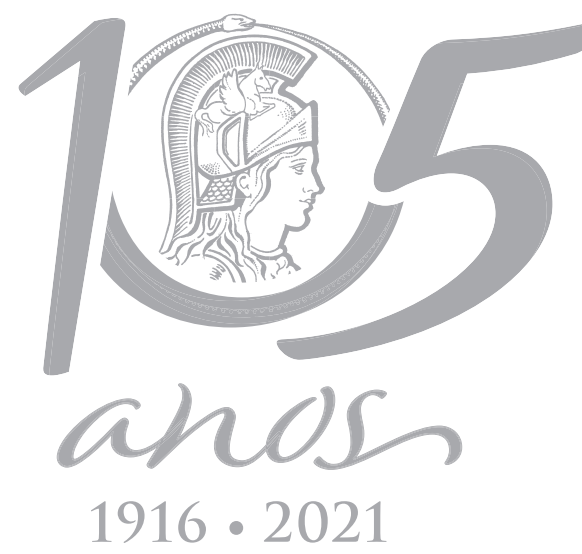

\title{
The 100,000 most influential scientists rank: the underrepresentation of Brazilian women in academia
}

\author{
LETICIA DE OLIVEIRA, FERNANDA REICHERT, EUGENIA ZANDONÀ, ROSSANA C. \\ SOLETTI \& FERNANDA STANISCUASKI
}

\begin{abstract}
Despite the progress observed in recentyears, women are still underrepresented in science worldwide, especially at top positions. Many factors contribute to women progressively leaving academia at different stages of their career, including motherhood, harassment and conscious and unconscious discrimination. Implicit bias plays a major negative role in recognition, promotions and career advancement of female scientists. Recently, a rank of the most influential scientists in the world was created based on several metrics, including the number of published papers and citations. Here, we analyzed the representation of Brazilian scientists in this rank, focusing on gender. Female Brazilian scientists are greatly underrepresented in the rank (11\% in the Top 100,000; $18 \%$ in the Top 2\%). Possible reasons for this observed scenario are related to the metrics used to rank scientists, which reproduce and amplify the well-known implicit bias in peer-review and citations. Male scientists have more self-citation than female scientists and positions in the rank varied when self-citations were included, suggesting that self-citation by male scientists increases their visibility. Discussions on the repercussions of such ranks are pivotal to avoid deepening the gender gap in science.
\end{abstract}

Key words: Academic productivity, gender gap, citation metrics, self-citation, women in science.

\section{INTRODUCTION}

In Brazil, women are deeply underrepresented at the senior and leadership levels in academia, especially when considering decision-making positions (Valentova et al. 2017, Areas et al. 2020). The percentage of women disproportionately decreases as they progress in their careers, which is a globally-observed phenomenon (Frietsch et al. 2009) and known as vertical or hierarchical segregation (Rossiter 1982), scissors effect (van Vlooten 2005, Areas et al. 2020) or leaky pipeline (Pell 1996). Etzkowitz \& Ranga (2011) state that the leaky pipeline "emphasizes a linear progression through a series of staged roles within academia, with a loss of female talent at every critical transition". Several factors contribute to women progressively leaving academia throughout their careers, such as motherhood, domestic labor, child and/or elder care (Machado et al. 2019, Karasik et al. 2015, Frietsch et al. 2009), harassment (National Academies of Sciences, Engineering, and Medicine 2018 ) and conscious and unconscious gender bias (Moss-Racusin et al. 2012, Reuben et al. 2014, Gaston 2015, Carli et al. 2016). Throughout history, women scientists have been ignored or denied credit, receiving less recognition and acknowledgment for their research findings than their male counterparts, which is known as the Matilda effect (Rossiter 1993). Implicit bias against women, which is an 
unconscious belief that women are less capable than their male peers, causes considerable damage to the progress of their scientific careers (Moss-Racusin et al. 2012, Dutt et al. 2016, Kuo 2016). For instance, experimental studies have shown that CVs with a male name are evaluated as more competent and deserving a higher salary than the same CV with a female name (Moss-Racusin et al. 2012, Eaton et al. 2020).

A traditional way to measure productivity and prestige in academic science is through publications and citations (Murray \& Graham 2007), which are used to evaluate scientists for hiring, promotion, and funding (West et al. 2013). As an example, among first-time Principal Investigators awarded with all types of National Institutes of Health $(\mathrm{NIH})$ grants from 2006 to 2017 , women received a median of $\$ 126,615$ vs. $\$ 165,721$ for men (Oliveira et al. 2019). These funding disparities may compromise women's future research performance, making them less competitive and thus harming their persistence in academia. High-impact journals, such as those from the Nature group, have much less women as senior authors (18.1\% in the last authorship), proportion that decreases with increasing impact factor of the journal (Bendels et al. 2018). Importantly, however, when articles are reviewed anonymously (double-blind review), the number of articles published with women as first authors increases (Budden et al. 2008). In addition, articles with women as leading authors are less cited than those with men as the leading author (Larivière et al. 2013, Dworkin et al. 2020, Elsevier 2020). All of these examples highlight how implicit bias can negatively impact the publication and citation processes.

Recently, a rank identifying the 100,000 most influential scientists in the world was published (Ioannidis et al. 2019, 2020). This list can have a great impact on the career of scientists, as such visibility can have implications for networking and for obtaining research funding. The authors used Scopus data to identify a database of the 100,000 most cited authors in all scientific areas based on a composite indicator that considers six citation metrics: (1) total citations; (2) Hirsch h-index; (3) coauthorship-adjusted Schreiber hm-index; (4) number of citations of singleauthor papers; (5) number of citations of singleauthor or first-author papers; and (6) number of citations of single-author, first-author, or last-author papers (Ioannidis et al. 2016). They provided ranks with and without self-citations. Moreover, they presented a rank that considers the Top $2 \%$ scientists of their main subfield disciplines. Ranks are presented for career-long and single-year impact. Here, we analyzed the representation of Brazilian scientists by gender in the database built by Ioannidis et al. (2020) to investigate a possible underrepresentation of women scientists. Our results revealed that female scientists are greatly underrepresented in the ranks in all domains, or even completely absent in some scientific fields. We discuss the nuances of gender-biased scientific elite and the validity of the metrics typically used to evaluate and score academics.

\section{MATERIALS AND METHODS}

The study was based on the publicly available database of 100,000 top scientists developed by Ioannidis et al. $(2019,2020)$. The database was downloaded from https://data.mendeley. com/datasets/btchxktzyw/2 (Baas et al. 2020). This database shows the five domains, 20 fields and 174 subfields of scientists and presents two independent ranks: (1) Top 100,000 rank and (2) a rank that considers the Top 2\% scientists of their main subfield disciplines. Ranks are described including or excluding self-citations, considering the career-long (Career dataset) or 
single-year impact (2019). The Career dataset considers publications and citations from 1960 to 2019, while the single-year dataset considers the metrics only for 2019. As we aimed to analyze the representation of Brazilian scientists by gender, all datasets were first filtered by "Country", in order to select only those affiliated to Brazilian institutions. Since there is no explicit information on gender in the datasets, gender was attributed to each of the scientists listed based on their first names. Ideally, an inclusive gender classification system should be used. Unfortunately, based on information available in the database used in this study, it was only possible to use the binary classification (male or female), since first names are embedded into the gender binary. This is a limitation, but as long as datasets lack gender identification, name-based gender inference remains the method of choice for plenty of applications, including studies of women's representation in science (Santamaría \& Mihajjević 2018). We manually labeled the first names as male or female according to Brazilian culture, where names are commonly genderspecific. When only the initials were available or in case of uncommon first names, we performed an internet search (i.e., Google Scholar, Curriculum Lattes platform, Research Gate, LinkedIn, universities websites, etc.) to confirm the gender identity of the researcher, crossing multiple information available on the database (last name, initials, affiliation institution and research field). We could not assign gender for only one of the Brazilian researchers listed in the database due to the impossibility of finding the researcher's first name. Three Brazilian scientists were duplicated in the single Year dataset. For the analysis performed here, the duplicated entries were excluded. To analyze the representation of Brazilian scientists in the two ranks (Top 100,000 rank and the rank that considers the Top $2 \%$ scientists of their main subfield disciplines), we described the total number of Brazilian scientists and the number of male and female scientists in each rank. Moreover, data were analyzed considering career-long (Career dataset) and single-year impact (2019). We also analyzed separately the data that included or excluded self-citations. For the subsequent analysis, where we evaluated self-citation percentages, number of published papers, number of never-cited published papers and the scientific field, we combined all Brazilian scientists into one single list and analyzed them regardless of each rank they were originally from. The number of published papers, selfcitation percentage, scientific domain, field and subfield for each scientist are provided in the original database. The number of nevercited papers was calculated as the difference between the number of published papers and the number of cited papers from 1960 to 2019 that is provided in the database. To evaluate the impact of self-citation in rank position, we used the information of rank position present in the database for both conditions (including and excluding self-citations) and calculated the percentage of male and female scientists that increased, decreased or did not change their position in the rank.

A student's t-test was performed to evaluate statistical differences between men and women in the average self-citation index, the average number of papers published and the average number of papers never cited, including and excluding self-citations. The significance level was set at 0.05. All analyses were performed using SigmaPlot version 10.0, from Systat Software. 


\section{RESULTS}

\section{Representation of Brazilian scientists in the ranks}

In the Top 100,000 rank, excluding self-citations, there are 254 Brazilian scientists in the Career dataset and 352 in the Single Year dataset, representing $0.25 \%$ and $0.35 \%$, respectively, of the world's top 100,000 scientists. When selfcitations are included, the participation of Brazilian scientists increases to $0.3 \%$ (Career dataset, 302 scientists) and 0.39\% (Single year dataset, 391 scientists). In the rank that considers the Top $2 \%$ scientists of their main subfield disciplines, Brazilian researchers correspond to $0.38 \%$ (Career dataset, 600 scientists) and
0.53\% (Single year dataset, 853 scientists) of the world's most influential scientists (Figure 1).

When analyzing data by gender, we observed a significant disparity between men and women (Figure 1). In both Top 100,000 ranks, including and excluding self-citations, women represent only $11 \%$ of the Brazilian scientists in the Career dataset. In the Single Year dataset, women represent $15.1 \%$ of Brazilian researchers in the rank including self-citations, and $13.7 \%$ in the rank excluding self-citations. Although still greatly underrep resented, percentages of women are higher in the Top 2\% rank, representing 14.2\% and $18.1 \%$ of Brazilian scientists in the Career and Single Year datasets, respectively.

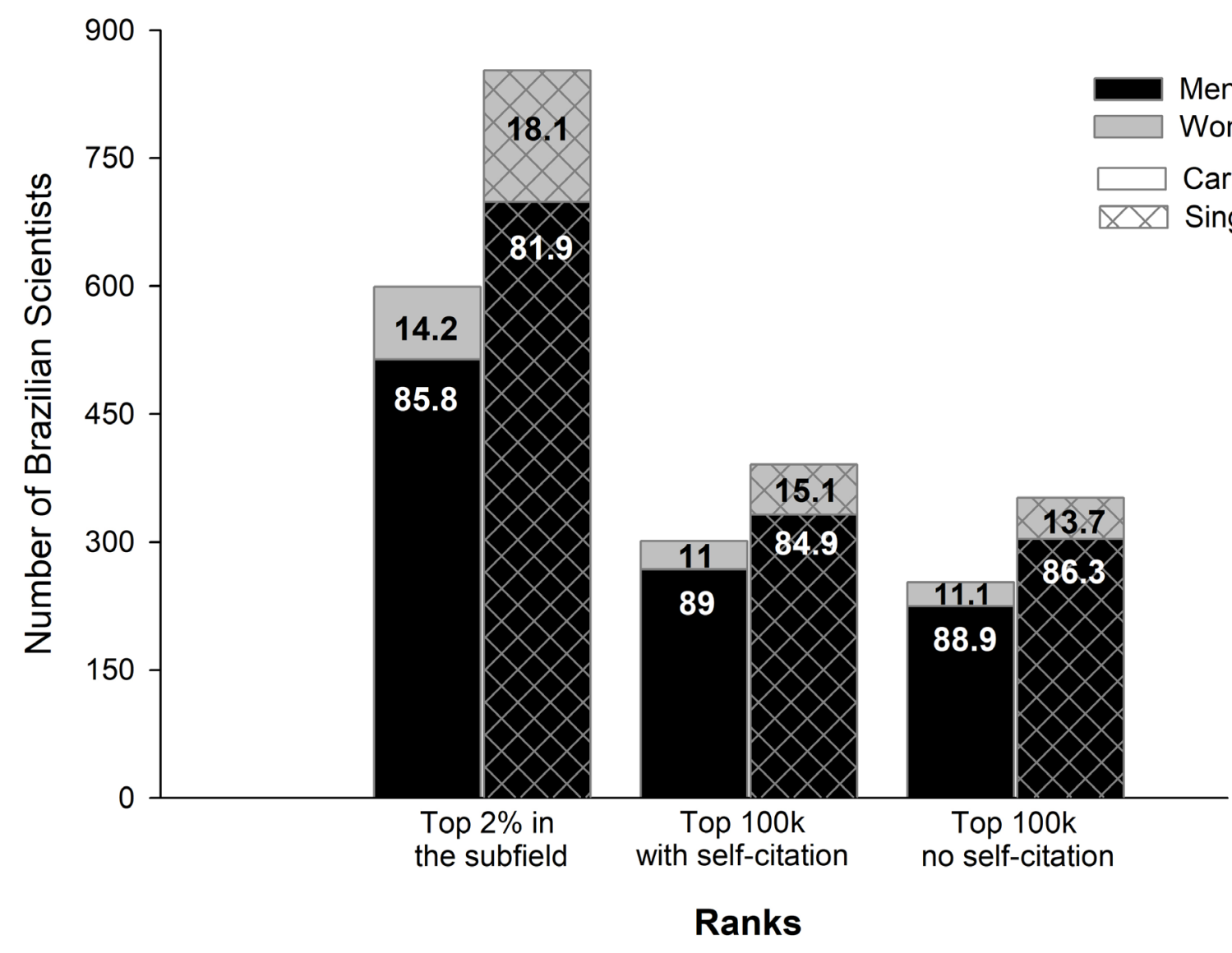

Figure 1. Representation of Brazilian researchers by gender in the Most Influential Scientists Rank. Number of Brazilian Scientists by gender in each of the ranks. Numbers in the bars indicate the percentage of male and female scientists. 


\section{Representation of Brazilian scientists by field}

The participation of Brazilian scientists in each scientific domain and field is presented in Table I. In total, regardless of the ranks they were originally from, there are 1022 Brazilian scientists in the database presented by loannidis et al. (2020). These scientists are distributed in all five scientific domains, but there is a great imbalance in the representation of each domain. The domains with the highest numbers of Brazilian scientists are Health Sciences, Natural Sciences, and Applied Sciences (with 384, 356 and 272 Brazilians respectively). The domains with the lowest representation of Brazilian scientists are Economic \& Social Sciences with eight, and Arts \& Humanities with only two. The highest percentage of Brazilian women was found in Health Sciences (21.9\% of Brazilian scientists). This percentage decreases to $17.3,13.8$ and $12.5 \%$ for Applied Sciences, Natural Sciences, and Economic \& Social Sciences, respectively. There are no Brazilian women in the Arts \& Humanities domain.

Brazilian scientists are represented in 18 of the 20 fields, with no representation in Communication \& Textual Studies and Visual \& Performing Arts. The fields with the highest number of Brazilians are Clinical Medicine, Chemistry, Physics \& Astronomy, and Biology (Supplementary Material - Figure S1). Considering gender, there are no Brazilian women in $30 \%$ of the fields, and there is no field with only female scientists. For the fields in which both male and female scientists are represented, the highest number of women is observed in Agriculture, Fisheries \& Forestry (27.5\%) and Public Health \& Health Services (25\%), while the lowest are in Physics \& Astronomy (5.8\%) and Engineering (8.1\%).

Considering the subfield classification, Brazilian scientists appear in 106 subfields, with the overall highest numbers in Dentistry (60 researchers), Tropical Medicine (49 researchers), and Medical \& Biomolecular Chemistry (42 researchers) (Figure S2). Brazilian women are not present in 51 (48\%) of the subfields. In contrast, only two subfields (1.9\%) - Nanoscience \& Nanotechnology and Anesthesiology - are only represented by Brazilian women. In the subfields where both men and women are represented, the highest numbers of women are in Nutrition \& Dietetics (75\%) and General Clinical Medicine (66.7\%). The lowest numbers of Brazilian women are observed for Nuclear \& Particle Physics (3.6\%) and Materials (4.5\%) subfields.

\section{Self-citation influence on Brazilian scientists impact}

Several factors influenced the inclusion of scientists in the ranks, including self-citations percentage. In general, Brazilians present a higher self-citation percentage (19.3\%) than the world's average (13.7\%). When factoring gender, there is a significant difference (Student's t-test, $p=0.008)$ between the self-citations percentage of female (18\%) and male (19.6\%) Brazilians (Figure 2a). Positions in the rank varied greatly when comparing the datasets that include or exclude self-citations (Figure 2b). Self-citation inclusion moved $67.7 \%$ and $61.9 \%$ of Brazilian male and female scientists up in the ranks, respectively, while 32 and $38.1 \%$ of Brazilian male and female scientists moved down in the ranks when self-citations were considered. On average, Brazilian scientists published fewer papers (173) between 1960 - 2019 compared to the world's average (198). A significant difference between the number of published papers was observed between male (180) and female (141) Brazilian scientists (Student's t-test, $p<0.001$; Figure $2 c$ ). It was interesting to note that the percentage of papers that were never cited was significantly higher for men $(21.6 \%)$ than that for women (19.1\%) when self-citations were not considered 
Table I. Brazilian scientists participation in the rank by domain and field.

\begin{tabular}{|c|c|c|c|}
\hline & Total (n) & Male (n, \%) & Female $(n, \%)$ \\
\hline & 1022 & $841(82.3)$ & $181(17.7)$ \\
\hline Health Sciences Domain & 384 & $300(78.1)$ & $84(21.9)$ \\
\hline Public Health \& Health Services & 16 & $12(75)$ & $4(25)$ \\
\hline Biomedical Research & 81 & $63(77.8)$ & $18(22.2)$ \\
\hline Clinical Medicine & 286 & $224(78.3)$ & $62(21.7)$ \\
\hline Psychology \& Cognitive Sciences & 1 & $1(100)$ & $0(0)$ \\
\hline Applied Sciences Domain & 272 & $225(82.7)$ & $47(17.3)$ \\
\hline Agriculture, Fisheries \& Forestry & 69 & $50(72.5)$ & $19(27.5)$ \\
\hline Enabling \& Strategic Technologies & 85 & $69(81.2)$ & $16(18.8)$ \\
\hline Information \& Communication Tech & 40 & $34(85)$ & $6(15)$ \\
\hline Engineering & 74 & $68(91.9)$ & $6(8.1)$ \\
\hline Built Environment \& Design & 4 & $4(100)$ & $0(0)$ \\
\hline Natural Sciences Domain & 356 & $307(86.2)$ & $49(13.8)$ \\
\hline Chemistry & 113 & $86(76.1)$ & $27(23.9)$ \\
\hline Earth \& Environmental Sciences & 26 & $22(84.6)$ & $4(15.4)$ \\
\hline Biology & 95 & $83(87.4)$ & $12(12.6)$ \\
\hline Physics \& Astronomy & 104 & $98(94.2)$ & $6(5.8)$ \\
\hline Mathematics \& Statistics & 18 & $18(100)$ & $0(0)$ \\
\hline Economic \& Social Sciences Domain & 8 & $7(87.5)$ & $1(12.5)$ \\
\hline Economics \& Business & 6 & $5(83.3)$ & $1(16.7)$ \\
\hline Social Sciences & 2 & $2(100)$ & $0(0)$ \\
\hline Arts \& Humanities Domain & 2 & $2(100)$ & $0(0)$ \\
\hline Historical Studies & 1 & $1(100)$ & $0(0)$ \\
\hline Philosophy \& Theology & 1 & $1(100)$ & $0(0)$ \\
\hline Communication \& Textual Studies & 0 & $0(0)$ & $0(0)$ \\
\hline Visual \& Performing Arts & 0 & $0(0)$ & $0(0)$ \\
\hline
\end{tabular}

The total number of scientists from each category is presented as (n). Gendered data are shown as percentage (\%) from the Brazilian scientists in the same domain or field. 
(Student's t-test, $\mathrm{p}<0.05$; Figure $2 \mathrm{~d}$ ). If selfcitations are considered, there is no longer a significant difference between the percentage of never-cited papers for male (17\%) and female (15.4\%) Brazilian scientists (Student's t-test, $p=$ $0.11)$.

\section{DISCUSSION}

In the present study we investigated the representation of Brazilian scientists in the a

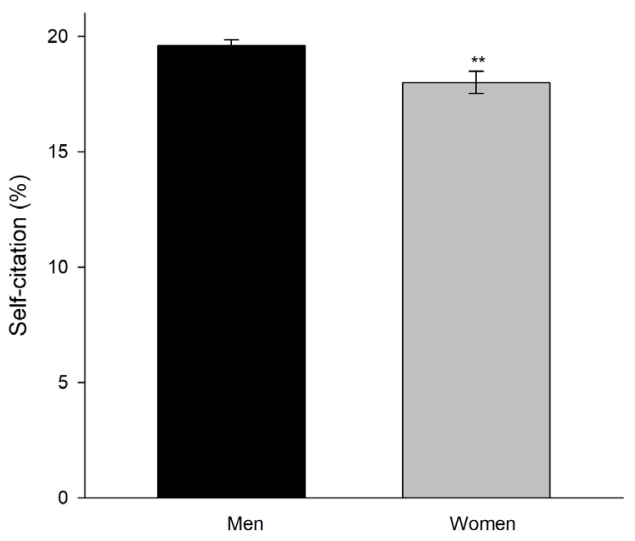

recent rank of the 100,000 most influential scientists in the world (Ioannidis et al. 2020), mostly focusing on a gender perspective. We found that Brazilians represent a very small percentage of scientists listed in the database (the highest percentage being only $0.53 \%$ for the single year dataset). When analyzing the datasets by gender, as expected, we found that women are greatly underrepresented. Among Brazilian scientists figuring the ranks, women account for as low as 11\% (Top 100,000 rank Career dataset) and no higher than 18\% (Top b
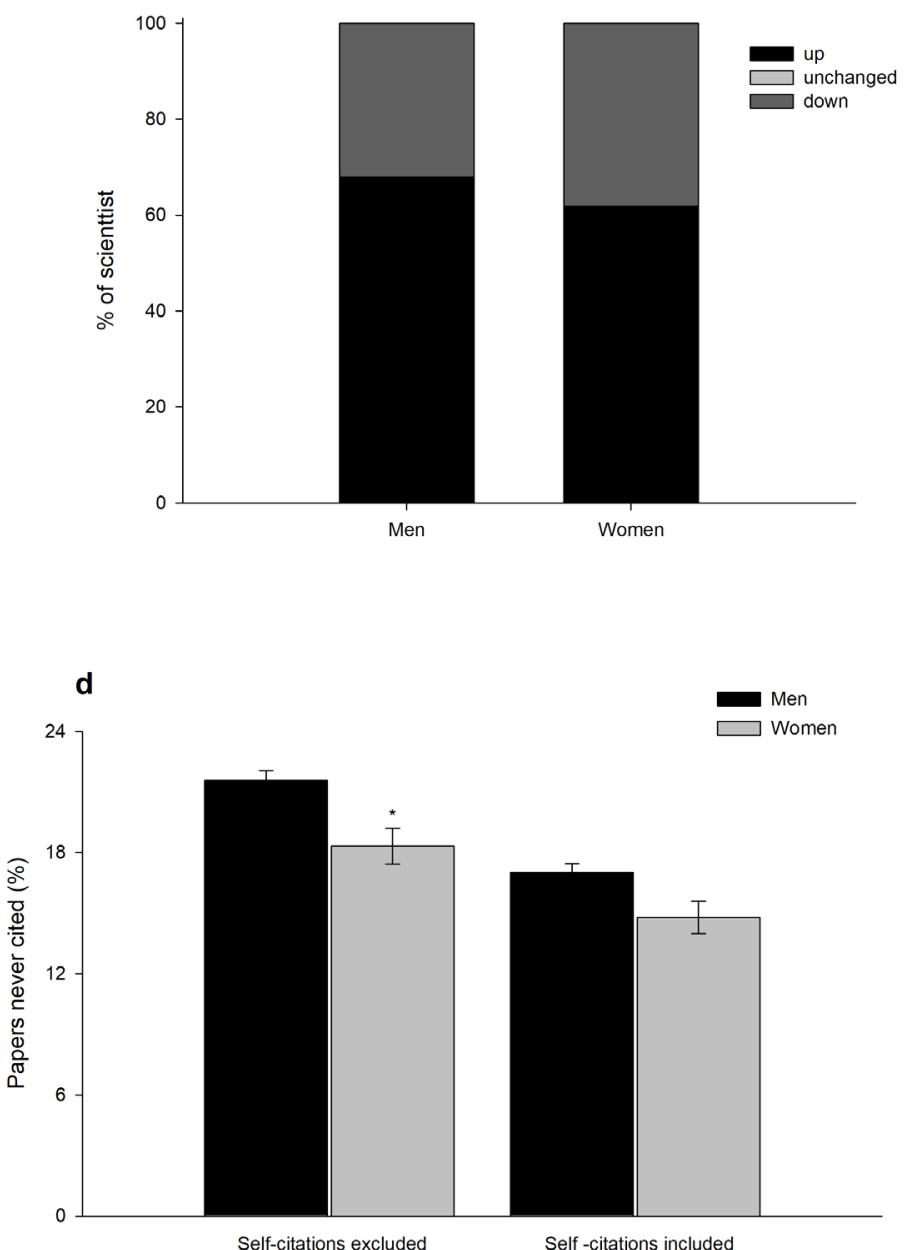

C

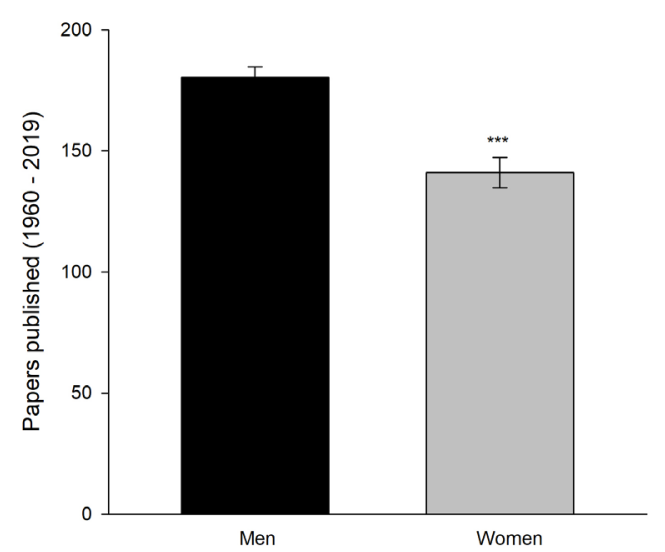

Self -citations included

Figure 2. Number of published papers and self-citation impact by gender. a. Percentage of self-citations by Brazilian scientists by gender. b. Rank position changes after the inclusion of self-citations. (c) Number of papers published between 1960 and 2019. (d) Number of papers published between 1960 and 2019 that were never cited, including and excluding self-citations. Data are shown as percentage (b) or mean \pm standard error (a, c, d). Statistical differences between means were analyzed using Student's t-tests $\left({ }^{*} p<0.05,{ }^{* *} p<0.01,{ }^{* *} p<0.001\right)$. 
2\% rank - Single Year dataset). Brazilian women are underrepresented in all areas and are completely absent in some fields and subfields, even some that typically show high percentages of women, such as those related to Arts \& Humanities (Barros \& Mourão 2020).

Brazil contributes with highly relevant research in several fields, such as in Medicine, Nursing, Physics \& Astronomy and Dentistry (McManus et al. 2020). These fields are indeed those with the highest number of Brazilian scientists in the ranks. On the other hand, the impact of Brazilian research is lower for Social and Human Sciences (McManus et al. 2020), which is confirmed by the low representation of Brazilians for these fields in the Ioannidis et al. (2020) ranks. A recent analysis by Santiago et al. (2020) showed significant disparities in the number of women holding a Ph.D. between areas in Brazil, with a predominance in the Humanities (19.8\% of women Ph.D.), and a very small presence in Engineering (4.3\%). In contrast, the number of female Brazilian scientists present in the ranks analyzed here does not reflect this pattern, since the lowest representation observed was in the Economic \& Social Science and Arts \& Humanities domains. However, the presence of Brazilian scientists in these two domains is particularly low, which is a result that merits a more in-depth investigation.

Our results also corroborate findings in the literature that women are underrepresented in science, especially in top positions. This phenomenon has been previously reported as a scissors effect or leaky pipeline in the scientific career of women (van Vlooten 2005, Frietsch et al. 2009, Etzkowitz \& Ranga 2011). Specific to the Brazilian scenario, women are the majority when entering the scientific career, representing $53 \%$ of graduate students. However, their participation decreases greatly as the career progresses, i.e. women represent $36 \%$ of research fellowship grants recipients from the Conselho Nacional de Desenvolvimento Científico e Tecnológico CNPq, $16 \%$ of the presidents of the Sociedade Brasileira para o Progresso da Ciência - SBPC and $0 \%$ of presidents of the Academia Brasileira de Ciências - ABC or CNPq (Areas et al. 2020). Possible explanations for the scissor effect in science are several and not yet fully understood. Differences in family duties (Jolly et al. 2014), in funding (Pohlhaus et al. 2011), in networking (Uhly et al. 2015), and the negative effect of implicit bias and gender role stereotypes (MossRacusin et al. 2012, Dutt et al. 2016, Kuo 2016) are all factors that could perpetuate women underrepresentation.

The underrepresentation of Brazilian women among the top 100,000 scientists ranking can reduce their visibility, especially for those in leadership positions. This can potentially create a vicious circle, where a lower perceived academic performance leads to less visibility, making it even more difficult to increase productivity (Bol et al. 2018, Astegiano et al. 2019). Specifically, gender negatively affects academic position, which harms the researchers performance, strengthening a lower status (van den Besselaar \& Sandström 2017). This pattern could be reinforced when using productivity metrics that have a gender bias. For instance, women publish less as first and last authors and are less cited (Bendels et al. 2018, Larivière et al. 2013, Dworkin et al. 2020, Elsevier 2020), thus using metrics that are just based on the number of publications and citations reproduces and reinforces the observed gender disparity in academia. Therefore, as the metrics used by Ioannidis et al. $(2019,2020)$ have a gender bias, by construction, the list of the most influential scientists will be composed in its majority by male scientists. Using exclusively this type of metric only reinforces gender bias in science. 
When we analyzed the effect of selfcitation with a gender perspective, we found that male Brazilian scientists in the rank have a significantly higher self-citation index than their women peers. This was also observed in an analysis of 1.5 million papers published between 1779 and 2011, where men were found to cite their own papers much more frequently than women (King et al. 2017). Moreover, our results showed that self-citations affected the position of the scientists in the rank, where self-citation increases the visibility of male scientists. Furthermore, Brazilian male scientists produce more papers never cited, especially when self-citations were not included. The percentage of uncited papers of Brazilian men is comparable to a global trend - 39 million research papers across all disciplines recorded in Web of Science from 1900 to the end of 2015 - where around $21 \%$ of papers have no citations (van Noorden 2017). However, even when women's publication metrics (number of papers published and number of citations) are similar to those of their men peers, they are still less likely to become research leaders (Van Dijk et al. 2014). An analysis of almost 24,000 applications submitted to the Canadian Institutes of Health Research (CIHR) showed that when applications were evaluated primarily based on the quality of the science, the predicted probability of success was 0.9 percentage points lower for female than male applicants. However, when the evaluations were based primarily on the PI leadership and expertise, the gender gap increased to 4 percentage points (Witteman et al. 2019). Importantly, when evaluation committees of funding agencies are aware of gender bias against women, the unequal distribution of funding between men and women is less likely to occur (Régner et al. 2019).

Recently, Huang et al. (2020) suggested that the gender differences observed in productivity and research impact are explained by differences in publishing career lengths and dropout rates. They found that the gradual increase in women's presence in STEM over the past 60 years was paradoxically accompanied by an increased gender difference in productivity and impact, particularly among the highly productive authors. Women and men scientists publish a comparable number of papers per year and have equivalent career-wise impact for the same amount of work. However, the differences were found in gender-specific dropout rates and the subsequent gender gaps in publishing career length and total productivity. They suggested that the community should strive to prevent women's loss at all stages of their careers, not just junior scientists. All these examples show that implicit bias and other factors, sometimes not identified, are greatly impacting the career of women scientists, creating a series of obstacles for their permanence in academia.

In summary, we found that female Brazilian scientists are greatly underrepresented in the ranks described by the Ioannidis et al. (2020) dataset. It is important to highlight that we are not questioning the merit of those Brazilian researchers listed in the top 100,000 scientists rank. Brazil has been suffering an ever-increasing lack of funding for science and research in general, and in this context, having their international impact recognized indeed reflects the excellence of these scientists. Nevertheless, it is necessary to discuss how factors beyond merit and excellence drive the exclusion of women from such ranks. Considering the arguments presented here, we suggest that top scientists rankings, such as that of loannidis et al (2020), should be published by gender. In this way, prominent women scientists could be "unmasked" by giving visibility to their scientific contributions. Additional recommendations (based on Calaza 
et al. 2021) are: (1) editors of scientific journals should establish a minimum of publications by women as first/last authors and fulfill this goal; (2) make double-blind reviews whenever possible; (3) evaluation/review committees, as well as editorial boards, must be balanced in its race, ethnic and gender composition and must be aware of the implicit bias phenomenon; (4) funding agencies, universities, and research institutions must promote educational programs that evaluate implicit (or explicit) bias among the members of committees as well as teach strategies to minimize it. We believe these recommendations would help to break the cycle women scientists face: "less visibility - less publication and citation - less financial grants - less visibility". If gender is not considered an important factor in analyzing these ranks, we are deepening gender disparities in science, which is no longer acceptable. It is time to make science a fairer environment for the present and future generations.

\section{Acknowledgments}

We would like to thank our children who are the reason why we keep on fighting for a fairer world. FR acknowledges the financial support of the Conselho Nacional de Desenvolvimento Científico e Tecnológico CNPq under the grant number 436344/2018-1. LO and EZ were supported by grants from CNPq, CAPES, and FAPERJ. EZ was also supported by Prociência UERJ.

\section{REFERENCES}

AREAS R, ABREU ARP, SANTANA AE, BARBOSA MC \& NOBRE C. 2020. Gender and the scissors graph of Brazilian science: from equality to invisibility. OSF Preprints. Available at https://osf.io/m6eb4.

ASTEGIANO J, SEBASTIAN-GONZALEZ E \& CASTANHO CT. 2019. Unravelling the gender productivity gap in science: a metaanalytical review. R Soc Open Sci 6: 181566.

BAAS J, BOYACK K \& IOANNIDIS JPA. 2020. Data for "Updated science-wide author databases of standardized citation indicators". Mendeley Data V2: 10.17632/ btchxktzyw.2.
BARROS SCV \& MOURÃO L. 2020. Gender and science: An analysis of brazilian postgraduation. Estud Psicol (Campinas) 37: e180108.

BENDELS MHK, MÜLLER R, BRUEGGMANN D \& GRONEBERG DA. 2018. Gender disparities in high-quality research revealed by Nature Index journals. PLOS ONE 13(1): e0189136.

BOL T, DE VAAN M \& VAN DE RIJT A. 2018. The Matthew effect in science funding. Proc Natl Acad Sci USA 115(19): 4887-4890.

BUDDEN AE, TREGENZA T, AARSSEN LW, KORICHEVA J, LEIMU R \& LORTIE CJ. 2008. Double-blind review favors increased representation of female authors. Trends Ecol Evol 23(1): 4-6.

CALAZA K ET AL. 2021. Facing Racism and Sexism in Science by Fighting against Social Implicit Bias: A Latin and Black Woman Perspective. Front Psychol 12: 671481. doi: 10.3389/fpsyg.2021.671481.

CARLI LL, ALAWA L, LEE Y, ZHAO B \& KIM E. 2016. Stereotypes about gender and science: Women $\neq$ scientists. Psychol Women Quart 40: 244-260.

DUTT K, PFAFF DL, BERNSTEIN AF, DILLARD JS \& BLOCK CJ. 2016. Gender differences in recommendation letters for postdoctoral fellowships in geoscience. Nat Geo 9(11): 805-808.

DWORKIN JD, LINN KA, TEICH EG, ZURN P, SHINOHARA RT \& BASSETT DS. 2020. The extent and drivers of gender imbalance in neuroscience reference lists. Nat Neurosci 23: 918-926.

EATON AA, SAUNDERS JF, JACOBSON RK \& WEST K. 2020. How gender and race stereotypes impact the advancement of scholars in STEM: Professors' biased evaluations of physics and biology post-doctoral candidates. Sex Roles 82(3-4): 127-141.

ELSEVIER. 2020. The Researcher Journey Through a Gender Lens. Available at https://www.elsevier.com/connect/ gender-report.

ETZKOWITZ H \& RANGA M. 2011. Gender dynamics in science and technology: From the "leaky pipeline" to the "vanish box”. Brussels Econ Rev 54(2/3): 131-147.

FRIETSCH R, HALLER I, FUNKEN-VROHLINGS M \& GRUPP H. 2009. Gender-specific patterns in patenting and publishing. Res Policy 38(4): 590-599.

GASTON N. 2015. Why is science sexist? BWB Texts Book, vol. 34.

HUANG J, GATES AJ, SINATRA R \& BARABÁSI AL. 2020. Historical comparison of gender inequality in scientific careers 
across countries and disciplines. Proc Natl Acad Sci USA 117(9): 4609-4616.

IOANNIDIS JPA, BAAS J, KLAVANS R \& BOYACK KW. 2019. A standardized citation metrics author database annotated for scientific field. PLoS Biol 17(8): e3000384.

IOANNIDIS JPA, BOYACK KW \& BAAS J. 2020. Updated sciencewide author databases of standardized citation indicators. PLoS Biol 18(10): e3000918.

IOANNIDIS JPA, KLAVANS R \& BOYACK KW. 2016. Multiple citation indicators and their composite across scientific disciplines. PLoS Biol. 14(7): e1002501.

JOLLY S, GRIFFITH KA, DECASTRO R, STEWART A, UBEL P \& JAGSI R. 2014. Gender differences in time spent on parenting and domestic responsibilities by high-achieving young physician-researchers. Ann Intern Med 160(5): 344-353.

KARASIK RJ, BERKE DL \& SCHEER SD. 2015. Caring for aging parents. Famili-friendly Policies and Practices in Academe: 69-89.

KING MM, BERGSTROM CT, CORRELL SJ, JACQUET J \& WEST JD. 2017. Men Set Their Own Cites High: Gender and Selfcitation across Fields and over Time. Socius: Sociol Res Dyn World 3: 1-22.

KUO M. 2016. Recommendation letters reflect gender bias. Science. Available at: https:// www.science mag.org/careers/2016/10/ recommendation-letters-reflect-gender-bias.

LARIVIĖRE V, NI C, GINGRAS Y, CRONIN B \& SUGIMOTO CR. 2013. Bibliometrics: Global gender disparities in science. Nat News 504(7479): 211.

MACHADO LS, PERLIN M, SOLETTI RC, KMETZCH L, SCHWARTZ IVD, SEIXAS A, RICACHENEVSKY F, TAMAJUSUKU ASK \& STANISCUASKI F. 2019. Parent in science: The impact of parenthood on the scientific career in Brazil. In Proceedings of the $2^{\text {nd }}$ International Workshop on Gender Equality in Software Engineering. GE 19: 37-40.

MCMANUS CM, NEVES AAB \& MARANHÃO AQ. 2020. Brazilian Publication Profiles: Where and How Brazilian authors publish. An Acad Bras Cienc 92: 1-22.

MOSS-RACUSIN CA, DOVIDIO JF, BRESCOLL VL, GRAHAM MJ \& HANDELSMAN J. 2012. Science faculty's subtle gender biases favor male students. Proc Natl Acad Sci USA 109(41): 16474-16479.

MURRAY F \& GRAHAM L. 2007. Buying science and selling science: gender differences in the market for commercial science. Ind Corp Change 16(4): 657-689.

NATIONAL ACADEMIES OF SCIENCES, ENGINEERING, AND MEDICINE. 2018. Sexual Harassment of Women: Climate,
Culture and Consequences in Academic Sciences, Engineering and Medicine. Washington, DC: The National Academies Press.

OLIVEIRA DFM, MA Y, WOODRUFF TK \& UZZI B. 2019. Comparison of National Institutes of Health Grant Amounts to FirstTime Male and Female Principal Investigators. J Am Med Assoc 321(9): 898-900.

PELL AN. 1996. Fixing the leaky pipeline: women scientists in academia. J Anim Sci 74(11): 2843-2848.

POHLHAUS JR, JIANG H, WAGNER RM, SCHAFFER WT \& PINN VW. 2011. Sex Differences in Application, Success, and Funding Rates for NIH Extramural Programs, Acad Med 86(6): 759-767.

RÉGNER I, THINUS-BLANC C, NETTER A, SCHMADER T \& HUGUET P. 2019. Committees with implicit biases promote fewer women when they do not believe gender bias exists. Nat Hum Behav 3(11): 1171-1179.

REUBEN E, SAPIENZA P \& ZINGALES L. 2014. How stereotypes impair women's careers in science. Proc Natl Acad Sci USA 111(12): 4403-4408.

ROSSITER MW. 1982. Women Scientists in America: Before Affirmative Action, 1940-1972. 2. Baltimore: Johns Hopkins University Press. ISBN 978-0801857119.

ROSSITER MW. 1993. The Matthew Matilda Effect in Science. Soc Stud Sci 23(2): 325-341.

SANTAMARÍA L \& MIHALJEVIĆ H. 2018. Comparison and benchmark of name-to-gender inference services. Peerj 4: e156

SANTIAGO MO, AFFONSO F \& DIAS TMR. 2020. Scientific production of women in Brazil. Transinformacao 32: e200032.

UHLY KM, VISSER LM \& ZIPPELKS. 2015. Gendered patterns in international research collaborations in academia. Stud High Educ 42: 760-782.

VALENTOVA JV, DA SILVA ML, OTTA E \& MCELLIGOTT AG. 2017. Underrepresentation of Women in the Senior Levels of Brazilian Science. PeerJ 5: e4000.

VAN DEN BESSELAAR P \& SANDSTRÖM U. 2017. Vicious circles of gender bias, lower positions, and lower performance: Gender differences in scholarly productivity and impact. PLOS ONE 12: e0183301.

VAN DIJK D, MANOR O \& CAREY LB. 2014. Publication metrics and success on the academic job market. Curr Biol 24(11): R516-R517.

VAN NOORDEN R. 2017. The Science that's Never Been Cited. Nature 552: 162-164. 
VAN VLOOTEN D. 2005. Cutting the gender scissors. Science. Available at https://www.sciencemag.org/ careers/2005/02/cutting-gender-scissors.

WEST JD, JACQUET J, KING MM, CORRELL SJ \& BERGSTROM CT. 2013. The role of gender in scholarly authorship. PLOS ONE 8(7): e66212.

WITTEMAN HO, HENDRICKS M, STRAUS S \& TANNENBAUM C. 2019. Are gender gaps due to evaluations of the applicant or the science? A natural experiment at a national funding agency. Lancet 393(10171): 531-540.

\section{SUPPLEMENTARY MATERIAL}

Figure S1. Representation of Brazilian researchers in the ranks by field and gender. Number of Brazilian Scientists in each of the scientific fields by gender. Numbers next to the bars indicate the percentage of female scientists. The two fields (Communication \& Textual Studies and Visual \& Performing Arts) in which there were no Brazilian scientists are not shown. Figure S2. Gender distribution among Brazilian Scientists in the subfields. Data is presented as the number of men and women in each of the subfields. Numbers next to the bars indicate the percentage of female scientists. Subfields in which there were no Brazilian scientists are not shown.

\section{How to cite}

OLIVEIRA L, REICHERT F, ZANDONÀ E, SOLETTI RC \& STANISCUASKI F. 2021. The 100,000 most influential scientists rank: the underrepresentation of Brazilian women in academia. An Acad Bras Cienc 93: e20201952. DOI 10.1590/0001-3765202120201952.

Manuscript received on December 22, 2020;

accepted for publication on April 26, 2021

\section{LETICIA DE OLIVEIRA ${ }^{1}$}

https://orcid.org/0000-0002-8450-2264

\section{FERNANDA REICHERT ${ }^{2}$}

https://orcid.org/0000-0002-5639-5879

\section{EUGENIA ZANDONÀ ${ }^{3}$}

https://orcid.org/0000-0003-4754-5326

\section{ROSSANA C. SOLETTI}

https://orcid.org/0000-0002-3353-3036

\section{FERNANDA STANISCUASKI ${ }^{5}$}

https://orcid.org/0000-0003-2155-1330

'Instituto Biomédico, Universidade Federal Fluminense, Rua Prof Hernani Melo, 101, 24210-130 Niterói, RJ, Brazil

${ }^{2}$ Escola de Administração, Universidade Federal do Rio Grande do Sul, Rua Washington Luiz, 855, 90010-460 Porto Alegre, RS, Brazil

${ }^{3}$ Departamento de Ecologia, Instituto de Biologia Roberto Alcantara Gomes, Universidade do Estado do Rio de Janeiro, Rua São Francisco Xavier, 524, 20550-013 Rio de Janeiro, RJ, Brazil

${ }^{4}$ Centro de Estudos Costeiros, Limnológicos e Marinhos, Campus Litoral Norte, Universidade Federal do Rio Grande do Sul, RS 030, Km 11.700, 95590-000 Tramandaí, RS, Brazil

${ }^{5}$ Departamento de Biologia Molecular e Biotecnologia, Instituto de Biociências, Universidade Federal do Rio Grande do Sul, Av. Bento Gonçalves, 9500, 91501-970 Porto Alegre, RS, Brazil

Correspondence to: Fernanda Staniscuaski

E-mail:fernanda.staniscuaski@ufrgs.br

\section{Author contributions}

All authors contributed equally to the manuscript. LO, EZ, FR, RCS, FS: Conceptualization, Data curation, Formal Analysis, Investigation, Methodology, Visualization, Writing - original draft, Writing - review \& editing.

\section{(cc) BY}

